\title{
EDUCAÇÃO AMBIENTAL NA INTRODUÇÃO À QUÍMICA NO ENSINO FUNDAMENTAL
}

\author{
Natana da Silva Lins ${ }^{1}$ \\ Osiel César da Trindade Junior ${ }^{2}$ \\ Antonia Gomes do Nascimento ${ }^{3}$
}

Resumo: A Educação Ambiental com o intuito de harmonizar os atos humanos entre sua própria espécie e com os demais seres vivos do ecossistema, objetiva a sensibilização do homem para que ele se perceba como parte integrante do Meio Ambiente. Sendo assim, objetivou-se analisar a metodologia pedagógica aplicada na abordagem da Educação Ambiental na introdução à Química na série do nono ano do Ensino Fundamental da escola Municipal Ney Braga na cidade de Governador Newton Bello (MA). Adotou-se como base a pesquisa exploratória, dispondo-se a coletar dados quantitativos e qualitativos por meio da aplicação de questionários com questões objetivas e discursivas. O período de observação, aliado à análise de questionários permitiu perceber que a interdisciplinaridade vem sendo trabalhada de forma eficiente na referida turma, durante a disciplina de Ciências, conforme orientada pela Lei no. $6.938 / 81$ e PCN's. Onde o docente sempre procura uma maneira de relacionar os conteúdos ministrados com temáticas voltadas ao meio ambiente, assim como associa aos problemas cotidianos dos alunos.

Palavras-chave: Prática Docente; Percepção Ambiental; Meio Ambiente.

\footnotetext{
${ }^{1}$ Instituto Federal de Educação, Ciência e Tecnologia do Maranhão - Campus Santa Inês. E-mail: natanalins@hotmail.com, Link para o Lattes: http://lattes.cnpq.br/2724023841181551

2 Instituto Federal de Educação, Ciência e Tecnologia do Maranhão - Campus Codó. E-mail: osiel.junior@ifma.edu.br, Link para o Lattes: http://lattes.cnpq.br/0098083142244230

${ }^{3}$ Instituto Federal de Educação, Ciência e Tecnologia do Maranhão - Campus São José de Ribamar. E-mail: antoniagomes@ifma.edu.br, Link para o Lattes: http://lattes.cnpq.br/9387285339621747
} 
Abstract: Environmental Education in order to harmonize human acts between its own species and with the other living beings in the ecosystem, aims at raising awareness among man so that he perceives himself as an integral part of the Environment. Thus, the objective was to analyze the pedagogical methodology applied in the approach of Environmental Education in the introduction to Chemistry in the series of the ninth grade of Elementary School of the Municipal School Ney Braga in the city of Governador Newton Bello (MA, Brazil). Exploratory research was adopted as the basis, and was willing to collect quantitative and qualitative data through the application of questionnaires with objective and discursive questions. The observation period, combined with the analysis of questionnaires, allowed us to realize that interdisciplinarity has been worked efficiently in that class, during the Science discipline, as guided by Law no. 6,938 / 81 and PCN's. Where the teacher always looks for a way to relate the contents taught with themes related to the environment, as well as associates to the students' daily problems.

Keywords: Teaching Practice; Environmental Perception; Environment.

\section{Introdução}

A compreensão de que a Terra é como um todo o Meio Ambiente, faz com que a integração da humanidade seja percebida como parte de algo maior. Onde somos dependentes de todos os outros seres, e ecossistemas. Essa percepção nos torna responsáveis pelo Meio Ambiente, por saber que ao preservá-lo, zelamos pela nossa própria existência.

Há muito tempo, o homem vem tratando o Meio Ambiente, como se ele não integrasse esse imenso sistema. Não se percebendo como parte do grande universo natural que compreende um conjunto formado pelo ambiente físico, os seres vivos e todos os fatores que nele atuam. Prova disso são as interações desregradas e a destruição da natureza. $O$ homem além de retirar do meio, bens para sua sobrevivência, busca por meio dessa atividade, acumular bens, riquezas e status diante de uma sociedade que precisa se auto afirmar diante de um consumismo desenfreado (FERREIRA, 2010).

Em busca de minimizar tais impactos é que a Educação Ambiental (EA) tem se mostrado importante aliada na preservação da vida. Sua inserção em todos os níveis de ensino é orientada pela Lei ㄲo. 6.938/81, que instituiu a Política Nacional de Meio Ambiente (PNMA). De acordo com os Parâmetros Curriculares Nacionais (PCNs), deve ser trabalhada na transversalidade e na interlocução entre as diferentes áreas do currículo escolar, portanto, não pode se constituir como disciplina autônoma.

A Educação Ambiental almeja uma harmonização dos atos humanos entre sua própria espécie e com os demais seres vivos do ecossistema. É com esse objetivo que se acredita que a Educação Ambiental deve ser trabalhada, pois se pretende não só a conscientização e um exame crítico da realidade que se observa, mas também o desenvolvimento da cidadania, da construção de 
valores sociais e o desenvolvimento de habilidades e consciência. Acredita-se, portanto, que se não houver Educação Ambiental, não há meio de garantir que haja conservação dos recursos naturais e da qualidade de vida para as gerações futuras.

A fim de realizar um panorama da Educação Ambiental vivenciada no cotidiano do ensino público, delimitou-se a proposta de um estudo das práticas efetivadas dentro e fora da sala de aula, no que tange ao ensino de Ciências. Obtendo o perfil da prática docente, as adversidades no fomento da EA, e proposições corretivas, além da obtenção da opinião e conhecimento do corpo discente.

Desse modo, analisar a metodologia pedagógica aplicada em escolas no que diz respeito à abordagem da Educação Ambiental se torna relevante, uma vez que sua função é contribuir para a formação de cidadãos conscientes, aptos a decidir e atuar na realidade socioambiental de um modo comprometido com a vida, com o bem-estar de cada um e da sociedade, local e global. Sendo assim, objetivou-se analisar a metodologia pedagógica aplicada na abordagem da Educação Ambiental na introdução à Química na série do nono ano do Ensino Fundamental da escola Municipal Ney Braga na cidade de Governador Newton Bello - MA.

\section{Metodologia}

\section{Descrição da pesquisa}

Adotou-se como base a pesquisa exploratória, dispondo-se a coletar dados quantitativos e qualitativos por meio da aplicação de questionários com questões objetivas e discursivas.

O público de interação foi dividido em duas categorias:

- Discentes: alunos do nono ano do Ensino Fundamental da escola municipal Ney Braga do município de Governador Newton BelloMA.

- Docente: leciona disciplina de Ciências do Ensino Fundamental da escola municipal Ney Braga do município de Governador Newton Bello-MA.

Foram elaborados dois questionários, um para cada categoria, estruturados da seguinte maneira:

- Para os discentes - 9 questões objetivas;

- Para o docente - 10 questões discursivas.

Após a aplicação dos questionários, as questões objetivas foram tabuladas, e as discursivas organizadas e analisadas. Utilizou-se ainda a observação como técnica de coleta de dados. 
$\mathrm{Na}$ aplicação da técnica utilizada, o investigador procura atender a um dos pressupostos fundamentais da Observação Participante, a saber: a convivência do investigador com a pessoa ou grupo em estudo proporciona condições privilegiadas para que o processo de observação seja conduzido de modo a possibilitar um entendimento genuíno dos fatos, que de outra forma não nos seria possível. (MÓNICO et al., 2017).

Os alunos foram observados durante as aulas de ciências por um período de uma semana. Foram ministradas 3 (três) aulas na turma, sendo duas em sala, e uma aula de campo.

\section{Análise dos dados}

As análises estatísticas das questões objetivas tabuladas foram realizadas no programa Microsoft Office Exce $^{\odot}{ }^{\odot}$ 2010. Para as demais questões foi realizada análise textual discursiva.

Tal qual explicitam Medeiros e Amorim (2017), a tônica dada pela Análise Textual Discursiva no processo de análise de dados qualitativos na pesquisa em Educação está na compreensão do objeto pesquisado. Entretanto, há de se destacar que a compreensão fundida caminha para a busca da transformação da realidade a partir das próprias perspectivas dos sujeitos que participam da investigação. Nesse sentido, exige-se uma interpretação, não partindo de fora do fenômeno investigado.

\section{Resultados e discussão}

\section{População e amostra}

\section{Perfil dos alunos}

Participaram da pesquisa 26 (vinte e seis) alunos, dos quais $57,70 \%$ (15 pessoas) são do gênero feminino, e 42,30\% (11 pessoas) são do gênero masculino. Estavam inseridos em uma única turma de nono ano do Ensino Fundamental da escola municipal Ney Braga do município de Governador Newton Bello (MA).

\section{Perfil do docente}

Participou da pesquisa o docente da disciplina de Ciências da referida escola, sendo este do gênero masculino, com 30 (trinta) anos de idade, graduado em licenciatura em química pelo Instituto Federal de Educação, Ciência e Tecnologia do Maranhão - Campus Zé Doca. 


\section{Percepção de Meio Ambiente e Educação Ambiental dos alunos do nono ano da escola municipal Ney Braga}

A percepção do meio natural tem sido abalada progressivamente nas últimas décadas. As pessoas que nascem em ambientes totalmente construídos têm uma tendência a perder muito de sua sensibilização e percepção em relação ao meio ambiente, o que dificulta a criação de vínculos suficientemente fortes para a construção de uma valoração mental dos elementos (MARCZWSKI, 2006).

A primeira questão aplicada com os alunos, possuía o objetivo de analisar a percepção deles quanto aos sujeitos que são afetados em decorrência dos problemas ambientais presentes no dia a dia. Os resultados podem ser observados no Gráfico 1, a seguir:

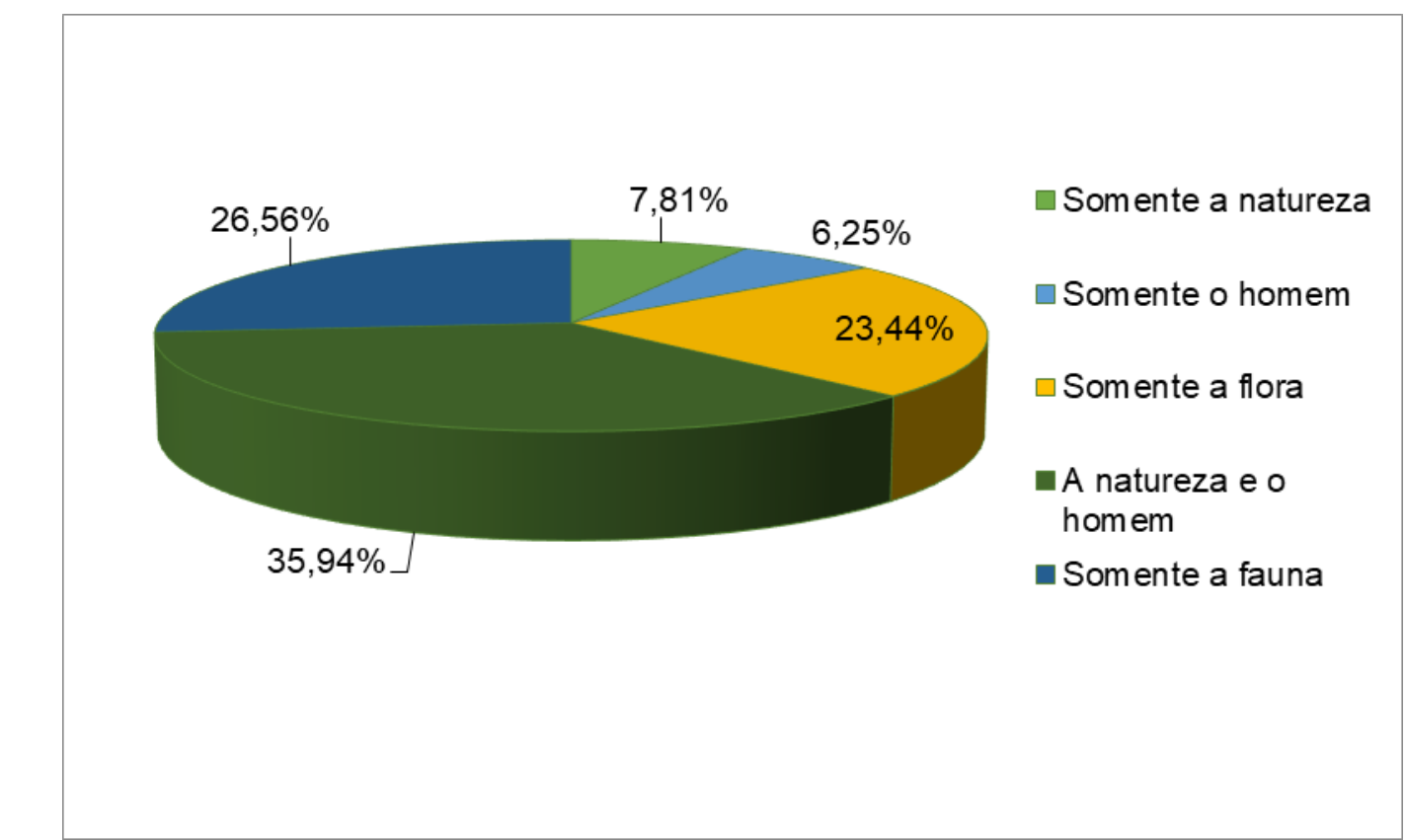

Gráfico 1: Percepção dos alunos sobre os sujeitos prejudicados com os problemas ambientais.

Fonte: autoria própria (2017).

Ao analisar o Gráfico 1, nota-se que uma quantidade considerável de alunos não se percebe como parte integrante do meio ambiente. Assim como possuem vaga noção de que sendo todos integrantes de um todo, todos os entes são prejudicados com o aumento dos problemas ambientais. Nota-se que existe uma grande tendência em associar meio ambiente apenas à recursos naturais.

Cavalheiro (2008) em sua pesquisa com alunos das últimas séries do ensino fundamental de uma escola estadual na cidade Santa Maria (RS), obteve resultados semelhantes para a mesma questão. $O$ autor considerou razoavelmente abrangente a percepção dos alunos sobre os problemas ambientais. 
No seu estudo constatou-se que os alunos têm uma percepção razoavelmente abrangente referente os problemas ambientais, visto que, a maioria dos alunos consideram errada a afirmação de que somente a natureza é parte dos problemas ambientais. No entanto, o homem, a natureza, os animais e vegetais, também não são únicos agentes causadores da problemática ambiental. Pois, o sistema socioeconômico vigente, através do poder econômico é um dos principais causadores do uso desordenado dos recursos naturais, devido a busca incessante da expansão dos seus negócios, sem preocupação com as consequências ambientais.

Tendo conhecimento disso, o resultado encontrado na primeira questão remete à necessidade de que a temática precisa ser abordada com mais frequência e de uma maneira que gere sentimentos de pertencimento.

Entender-se como ser social e atuante no meio em que se vive, onde as ações que ocorrem no momento atual podem interferir na vida de várias pessoas, conhecidas ou não, dentro da sociedade, o aluno torna-se mais consciente sendo este um grande desafio (SANTOS; COPETTI, 2015).

Segundo Lima (2010) os materiais educativos são dispositivos que legitimam e socializam saberes e práticas realizadas em uma determinada área, como o desenvolvimento sustentável. De acordo com os PCN's: "recursos didáticos como livros, vídeos, televisão, rádio, calculadora, computadores, jogos e outros materiais têm um papel importante no processo de ensino e aprendizagem" (BRASIL, 1998, p. 57).

Sabendo que os recursos didáticos são ferramentas imprescindíveis para auxílio no processo de ensino e aprendizagem, através da dinamização das aulas e, por conseguinte, levar a uma maior interação com o docente, buscou-se investigar, na segunda questão, se todos os alunos do estudo possuíam acesso a esses recursos.

Quando questionados quanto ao acesso permanente à recursos/materiais que contenham informações de Educação Ambiental, 77\% (20 alunos) dizem não ter acesso a esse tipo de material, 23\% (6 alunos) tem acesso permanente a este tipo de material. Um resultado bastante divergente do encontrado por Andrade e Musse (2014).

A diferença entre os dois grupos de alunos é significativa e desafiadora, visto que eles desempenham um papel fundamental no processo de ensino e aprendizagem. Sendo a falta de material uma das principais dificuldades para se trabalhar esses conteúdos (ALMEIDA, 2006).

Quanto mais informação circular a respeito da importância da preservação ambiental, mais cumplicidade com a natureza se criará nas sociedades (REIS, 2005). Daí a importância de se dispor de recursos que permitam o acesso dos alunos à essas informações.

Buscando entender a percepção individual sobre a relevância do tema para cada aluno, como é disposto na questão 3 , eles foram indagados quanto 
ao que achavam em relação a discussão dos problemas ambientais. Foram apresentadas na questão seis alternativas: ruim, ótimo, péssimo, importante, chato ou não tenho interesse. Todos os alunos marcaram a opção importante, demostrando que consideram como um assunto de relevância.

Considerar a discussão da problemática ambiental importante, é um ponto positivo. Uma vez que, acredita-se que considerando os temas ambientais assuntos de relevância, o interesse em adquirir conhecimento sobre a temática é aumentado. A curiosidade é o alimento do homem na tentativa de entendimento de seus ambientes, do seu universo atual, refletindo sobre a sua existência e procurando prever o seu futuro no planeta (BAUMGRATZ, 2014).

Ao serem indagados quanto aos assuntos relacionados à EA que eles têm interesse em discutir, todos marcaram mais de uma das opções contidas na questão, o que é satisfatório, pois demostra amplo interesse pela temática ambiental. O resultado está representado no Gráfico 2.

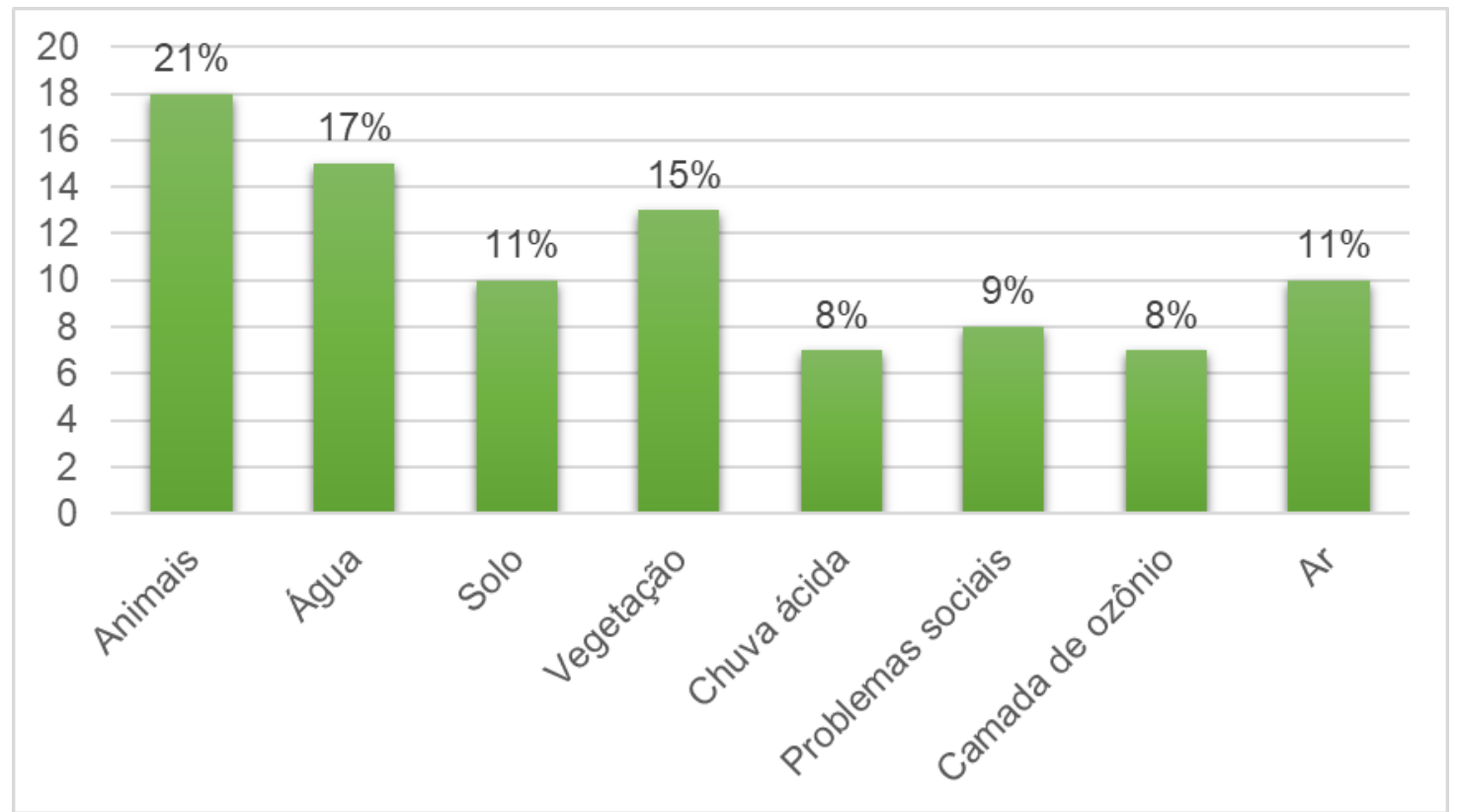

Gráfico 2: Assuntos que os discentes têm interesse em discutir.

Fonte: autoria própria (2017).

Para essa questão, 18 (dezoito) alunos marcaram mais de uma opção, demostrando interesse pelos mais variados temas. Ao analisar o gráfico, verifica-se a predominância pelos temas: animais (fauna), água e vegetação (flora). Resultado semelhante foi encontrado por Cavalheiro (2008), para a mesma a questão, com a maioria dos discentes optando pelo assunto água, seguido de animais.

No estudo realizado por Baumgratz (2014), em visitas realizadas ao Parque Nacional de Itatiaia, contatou-se que a maior parte das expectativas dos discentes dos últimos anos do ensino fundamental, estavam em torno de animais, plantas e cachoeiras. Ao visitarem o museu do parque, o interesse se 
concentrou em especial nas vitrines de animais $(56,6 \%)$. Para a autora o interesse pelos animais pode estar ligado às emoções despertadas nos alunos, ou à curiosidade.

É interessante observar a semelhança nos resultados obtidos nos três estudos realizados com um mesmo público (alunos do Ensino Fundamental II). Outra explicação para a predominância de interesse pelo tema animais, pode estar relacionado ao meio onde os discentes vivem, uma vez que no meio urbano possuem pouco contato com uma variedade maior de animais, assim como com os demais recursos naturais.

Com o intuito de avaliar o conhecimento dos alunos quanto às temáticas ambientais, aplicou-se uma pergunta que os questionava se a água potável do mundo pode chegar a acabar. Visto que a água potável já é um dos recursos naturais mais escassos (BOFF, 2009).

Além disso, Bacci e Pataca (2008, p.217) acreditam "que a água seja um tema de aproximação dos conhecimentos parcelares profundos e plurais e um tema que desenvolva a prática interdisciplinar."

É possível tratar o tema água desde as primeiras séries do ensino Fundamental até o ensino Médio com diferentes estratégias e recursos didáticos. Essa abordagem é necessária para atingir os objetivos pretendidos de formar cidadãos conscientes, capazes de julgar e avaliar as atividades humanas que envolvem o uso e a ocupação do ambiente, dentro e fora da comunidade em que estão inseridos (BACCl et al., 2009, p.44).

As respostas obtidas foram satisfatórias, 96\% (25 alunos) disse que a água potável pode acabar e apenas 4\% (1 aluno) respondeu que não. Sendo a água um tema que desenvolve a prática interdisciplinar, e possível de ser trabalhado desde as séries iniciais, através do resultado obtido acredita-se que a temática já foi trabalhada ao menos uma vez com esses alunos.

Valmorbida (2013) em seu estudo com alunos do Ensino Fundamental II, obteve resultados bastante diferentes para a mesma questão, onde $67 \%$ dos entrevistados disse que não acredita que a água potável possa acabar, e apenas $33 \%$ acreditava que a água potável pode acabar.

Para saber a forma como os alunos preferem discutir e assimilar as questões ambientais, a sexta questão dispunha de cinco alternativas, sendo que mais de uma poderia ser escolhida. Os resultados estão apresentados a seguir no Gráfico 3. 


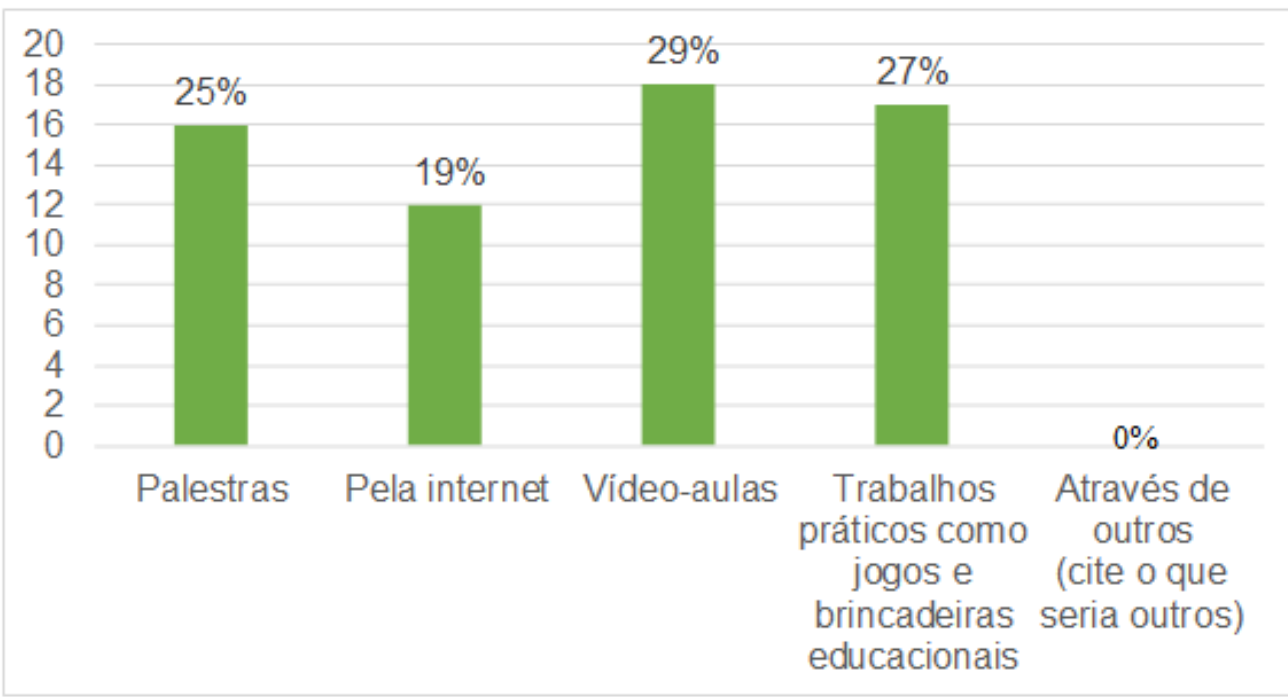

Gráfico 3: Meio de preferência dos alunos para assimilação das questões ambientais.

Fonte: autoria própria (2017).

Ao analisar o gráfico percebe-se que grande parte prefere assimilar as questões através de videoaulas. A segunda opção mais aceita pelos alunos sugere a assimilação dos conteúdos através de trabalhos práticos, assim como através de jogos e brincadeiras.

A assimilação da temática através de videoaulas é bastante interessante, pois torna possível que os alunos visualizem realidades diferentes das que estão habituados, podendo serem usadas como estratégia de sensibilização dos mesmos.

Para Moran (1995) os vídeos além de seduzirem, informam, entretêm e projetam no imaginário. E um recurso que pode ser utilizado pelo docente na estimulação dos alunos, visto que tornam a aula mais atrativa.

Seguindo a linha de pensamento de Santos (2008), pode-se justificar as preferências por atividades que envolvem a ludicidade pelo prazer que estas atrelam ao processo de ensino-aprendizagem.

O trabalho prático com jogos e brincadeiras educacionais, para discutir e assimilar as questões ambientais foi a preferência dos alunos que participaram da pesquisa realizada por Cavalheiro (2008), seguido de palestras.

No estudo realizado por Baumgratz (2014), com 22 docentes, e 91 (noventa e um) discentes das series finais do ensino fundamental, a crença de que as atividades lúdicas contribuem na aprendizagem foi apontada por $96,45 \%$ dos professores.

Sonda (2011) sugere a inserção de atividades práticas, como oficinas e projetos, por estimular alunos e professores no entendimento e compreensão das questões ambientais, e promover o envolvimento da escola possibilitando a interação entre todas as disciplinas. 
Tendo em vista que,

a inserção da dimensão ambiental nos currículos escolares para trabalhar Meio Ambiente como Tema Transversal pressupõe, necessariamente, uma construção conjunta, por uma equipe multidisciplinar, que caracterize as diferentes áreas do conhecimento e que possam contribuir para o tratamento da questão, bem como auxiliar na construção de mecanismos e instrumentos que possibilitam ao aluno o entendimento da realidade local (AMOÊDO, 2010, p.49).

Segundo os alunos, em resposta a questão 7 , os problemas ambientais já foram trabalhados com todos através de algum professor, demonstrando que todos durante a sua vida escolar já tiveram ao menos um professor que trabalhou a interdisciplinaridade.

O resultado da pergunta já era esperado, pois compreende-se que a

EA não pode se restringir somente a disciplinas como Geografia e Ciências, isso porque os problemas ambientais são muito complexos e possuem um caráter multidimensional, que possibilita que haja uma interação entre as diferentes fontes de conhecimento da escola (SILVA, 2008 apud SILVA, 2017, p.23).

Resultado semelhante foi encontrado por Valmorbida (2013) para a mesma questão em seu estudo, no qual obteve-se um total de $87 \%$ de afirmações dos alunos, que garantiram já terem visto assuntos sobre EA em séries anteriores. Dos 40 (quarenta) alunos entrevistados, somente 6 (seis) alunos responderam que nenhum professor trabalhou o tema.

Para verificar as possíveis atitudes que seriam tomadas por estes alunos caso se vissem diante de um problema ambiental, colocou-se uma situação-problema na oitava questão, onde indagava sobre qual tipo de atitude seria tomada por eles caso um riacho próximo de suas casas estivesse cheio de lixo jogado pelas pessoas do bairro.

Para essa questão, 53,84\% (14 alunos) marcaram duas opções, que foram: "Conversar com os moradores do bairro a não jogar lixo no rio" e "Entrar em contato com a secretaria de obras para remover o lixo do rio". Cerca de 30, $76 \%$ (8 alunos) optaram por apenas conversar com os moradores do bairro a não jogar lixo no rio, e 15,38\% (4 alunos) optaram apenas por entrar em contato com a secretaria de obras para remover o lixo do rio.

Entendendo que a partir da sensibilização dos indivíduos é possível tratar a causa do problema, considera-se a decisão de conversar com os moradores que praticam tal ato a única capaz de solucionar o problema. Assim como a decisão de entrar em contato com a secretaria de obras para a retirada do lixo, trata os efeitos, porém não eliminado a causa, o mesmo tornar-se-ia um 
problema recorrente. Foram animadores os resultados obtidos com essa questão.

Sabendo que a problemática do lixo é um tema de EA muito trabalhado no âmbito escolar, por envolver questões relacionadas não só ao meio ambiente, mas à saúde pública, política, cultura e problemas sociais (DACACHE, 2004). A última questão indagava-os quanto ao cuidado com o lixo.

Quando questionados se em suas casas há o cuidado de realizar a separação do lixo, 50\% (13 alunos) disseram que sim, e os outros $50 \%$ relataram que em suas respectivas casas não há esse cuidado. Porém é necessário levar em consideração que os alunos residem em uma cidade pequena, onde não há nenhum tipo de aterro, tampouco é realizada coleta seletiva, o lixo é descartado em lixões.

Entretanto é importante destacar que a comunidade onde os alunos estão inseridos, necessita de políticas públicas voltadas à problemática. Visto que pouco pode ser feito se os alunos e a comunidade não possuem meios de manterem um comportamento ambientalmente adequado. Esse é um dos motivos da problemática do lixo envolver tantos sujeitos e questões.

De acordo com Cache (2004), $76 \%$ do lixo coletado no Brasil é depositado em lixões, que são caracterizados pelo depósito do lixo no solo sem nenhuma medida de proteção ao meio ambiente ou à saúde pública.

\section{Educação Ambiental na prática docente}

$\mathrm{Na}$ abordagem de temas ambientais em sala da aula, o docente tem papel importante como mediador da construção de uma postura ética em relação à preservação do meio ambiente e no desenvolvimento da cidadania (CANESIN; SILVA; LATINI, 2010).

O professor acompanhado durante o estudo, possui formação em Licenciatura em Química, está há três anos exercendo a docência no município, o que responde a oitava questão da entrevista. De acordo com Canesin, Silva e Latini (2010, p.51) "o profissional da Química é um dos principais atores que pode atuar como um mediador da compreensão do meio ambiente e as suas relações com a Química."

O educador ambiental, além de promover o desenvolvimento de conhecimentos científicos prepara os estudantes para o exercício da cidadania, a fim de que compreenda não só seu papel na sociedade, mas também se habilite a transformá-la (ROCHA et al., 2016, p. 270). 
turmas de $6^{\circ}$ e $9^{\circ}$ ano na própria ementa de conteúdo. Procuro sempre abordagens práticas e sempre que possíveis aulas fora da escola".

Segundo Santos e Santos (2016 apud SILVA, 2017, p. 23), "a incorporação desses temas transversais na educação e previstos nos PCN's, explicitam que a questão ambiental deve ser trabalhada de forma contínua, sistemática, abrangente e integrada, e não como áreas ou disciplinas isoladas". $\mathrm{O}$ uso de abordagens mais práticas e fora do ambiente escolar, estimulam, e sensibilizam o aluno.

Segundo o docente, o mesmo obtém informações sobre EA em livros didáticos, na internet e TV. É importante que o docente esteja sempre em contato com esses recursos, de onde pode obter mais conhecimento acerca da temática.

Oliveira, Obara e Rodrigues (2007), acreditam que prender-se somente ao livro como fonte de conhecimento para Educação Ambiental, nega outros conhecimentos, como o conhecimento local, por exemplo, que são considerados de fundamental importância para a compreensão do mundo físico e social.

Tendo o docente acesso à tantos subsídios de caráter teórico, a inserção da temática ambiental nas aulas de ciências é facilitada, pois as discussões acerca do tema ficam mais abrangentes e condizentes com as realidades locais e mundiais.

Quando questionado sobre como observa os problemas ambientais que defrontamos o entrevistado disse que: "O grande desejo da humanidade é conciliar desenvolvimento com equilíbrio e não está sendo obtido com êxito. São sempre problemas graves, pois nem sempre podem ser corrigidos".

A fala do docente está em acordo com o pensamento de Ramos et al. (2009), quando diz que "o homem com suas ações é um ser impactante do meio ambiente". É importante saber a visão do docente a respeito da problemática, para entender a maneira como ele se posiciona, uma vez que na condição de professor, consegue influenciar seus alunos.

É possível perceber que o docente não possui uma visão conservacionista de Educação Ambiental como a descrita por Dias (2004), que de acordo com o autor não deve ser adotada pela escola, uma vez que seus ensinamentos não conduzem a mudança de valores e novas visões de mundo.

Educar para transformar e emancipar o sujeito se constitui em impositivo do nosso tempo, pois a práxis educativa é transformadora, oportunizando ao educador a oferecer as transformações pelas ações na realidade cotidiana (ROCHA et al., 2016, p. 276).

"O grande desafio está, [...] em fazer as pessoas compreenderem que proteger o meio ambiente traz benefícios diretos e imediatos à qualidade de 
vida delas mesmas que é útil" (REIS, 2005, p. 178). "Um pilar fundamentalmente importante para a estabelecer essa construção de valores dentro das instituições de ensino, é o educador" (SILVA, 2017, p.37).

Quando questionado se a abordagem da temática tem sido realizada de maneira satisfatória, respondeu: "Não. Porque o tempo é limitado. A disciplina em si (Ciências) não disponibiliza de um tempo suficiente para uma boa abordagem". A falta de tempo também foi apontada como um obstáculo na abordagem de temas relacionados a EA, no estudo realizado por Leite e Rodrigues (2013) com 13 professores de química do Ensino Médio.

A falta de tempo para se trabalhar temas de EA, é um dos maiores obstáculos da abordagem. Além deste obstáculo, Leite e Rodrigues (2013) em sua investigação também destacam a prioridade ao conteúdo, a transferência da responsabilidade a outras disciplinas, e o trabalho individual (que é quando os demais professores se abstêm de trabalhar o tema atribuindo a responsabilidade a apenas um docente), como os principais fatores que dificultam a abordagem da Educação Ambiental nas aulas.

"Para que se avalie a real representação social de meio ambiente são necessárias diferentes formas de perguntar" (CUNHA; ZENI 2007, p. 159). Pois para Baumgratz (2014, p. 164),

há uma tendência em responder de forma condizente com o que é considerado politicamente correto e aceito pela sociedade, nem sempre correspondendo ao que as pessoas pensam. Essas formas de perguntar podem se traduzir pela observação do grupo, suas falas informais, convivência e respostas por posturas adotadas frente aos acontecimentos, não apenas pelo que foi escrito.

Diante do pensamento da autora, fica explicita a importância do período de observação em sala de aula. Pois mesmo com a dificuldade relatada pelo docente no questionário, durante o período de observação das aulas ministradas por ele, notou-se grande empenho de sua parte para contextualizar os conteúdos trabalhados com o dia a dia dos alunos, e relacioná-los à questões ambientais sempre que possível.

A transmissão do conhecimento científico vinculado com a realidade cotidiana dos alunos, os incita a realização de ações concretas, iniciadoras de uma mudança comportamental individual e coletiva no que tange ao meio ambiente e outros temas (SANTOS, 2016).

A prática do docente encontra-se em acordo com a fala de Freire (2002), que diz ser necessário aproveitar as experiências de vida dos alunos em áreas de cidades descuidadas pelo poder público para discutir, como por exemplo, a poluição dos riachos e dos córregos e os baixos níveis de bemestar das populações, os lixões e os riscos que oferecem à saúde das pessoas. 
Pois ensinar exige respeito aos saberes dos alunos, os quais são necessários à prática educativa.

Ao ser indagado sobre qual assunto ele possui interesse em saber mais, o docente relatou: "Tratamento de lixo, em especial. Pois, por se tratar de uma cidade pequena (Governador Newton Bello/MA) as ações no que diz respeito ao reuso e destinação do lixo são sempre precárias e inadequadas.". De fato, a situação do lixo na referida cidade é negligenciada por parte das autoridades competentes, sendo o mesmo despejado em lixões a céu aberto.

O interesse do docente em se aprofundar na questão do lixo, pode ser benéfico não só para seus alunos, mas para toda uma comunidade que pode ser sensibilizada. Possibilitando assim a formação de cidadãos éticos e comprometidos para o bem da sociedade (SILVA; HAETINGER, 2012).

Apesar de ser um tema importante e que permite o desenvolvimento de várias práticas, deve-se tomar cuidado para não o tratar de forma asséptica e fragmentada, que, como todo saber tratado dessa maneira, cristaliza-se (BARIZAN; DAIBEM; RUIZ, 2003, p.09).

Segundo Layrargues (2011), apesar de ser um tema complexo, muitos programas escolares de Educação Ambiental são implementados de maneira reducionista. Onde os trabalhos são voltados somente para reciclagem, desenvolvem unicamente a Coleta Seletiva de Lixo, carentes de uma reflexão crítica e abrangente acerca dos valores culturais da sociedade de consumo, além dos aspectos políticos e econômicos relevantes na abordagem.

Atividades ambientais educativas escolarizadas, ainda que consideradas incipientes, têm se apresentado como práxis importante de contribuição à causa ambiental (GUIMARÃES et al. 2012, p.69).

Dentre os projetos que já são realizados na escola o docente relata o: "Lixo: problema de todos", onde há a realização de visita ao lixão municipal. De acordo com Portilho (1997) as práticas realizadas em Educação Ambiental direcionadas para a problemática dos resíduos sólidos são um campo fértil de trabalho. Para Dacache (2004), a visita ao lixão é muito impactante, e alcança o intuito de sensibilização. Todo proveito que se puder extrair da visita deve ser explorado, exercitando os sentidos e a capacidade do grupo de questionamento perante o que é percebido (BAUMGRATZ, 2014).

No estudo realizado por Baumgratz (2014), 81,8\% dos docentes que participaram mencionam haver projetos em suas respectivas escolas a respeito do lixo. 
"A participação de um projeto qualifica a visita, conferindo-Ihe responsabilidade, comprometimento com o ensino e veracidade no conteúdo" (BAUMGRATZ, 2014, p. 157). Torna possível o contato do aluno com tudo aquilo que já foi trabalhado em sala de aula.

"Os educadores ambientais têm, nos projetos interdisciplinares, a expectativa de mudança de todo o processo de formação de sujeitos capazes de interferência social" (GUIMARÃES et al., 2012, p.70). Os projetos interdisciplinares configuram uma das estratégias mais utilizadas para inserção da EA nas escolas brasileiras de ensino fundamental (VEIGA; AMORIM; BLANCO COSSÍO, 2005).

Outro projeto relatado pelo docente foi o: Todos contra a dengue. Onde são realizadas caminhadas por bairros, e abordagens sobre cuidados com 0 meio ambiente. Durante o período, em que se acompanhou a referida turma, pôde-se participar deste projeto onde foi realizada distribuição de panfletos pelas ruas da cidade, e pessoas foram abordadas para explicações de cuidados com o meio ambiente.

Considera-se a distribuição de panfletos aliada ao diálogo, como foi realizada pela referida turma uma maneira eficaz de abordagem do tema para a comunidade. Uma vez que já foi constatado por Teixeira e Souza (2015) que somente a distribuição de materiais contendo informações, sem discussão e sem uma contextualização, não agrega melhoras consideradas significativas em níveis de conhecimento e atitudes.

Ao contrário da maioria dos professores, que de acordo com Almeida (1997 apud BAUMGRATZ, 2014) na prática não preparam seus alunos para as visitas e atividades extraclasse. No estudo pode-se ver alunos preparados pelo professor para a atividade que estava sendo realizada.

Trabalho semelhante ao realizado pelo docente foi realizado por Morais, Barbosa e Alves (2016), na cidade de Apodi (RN) onde após a realização de um projeto envolvendo a escola, saíram as ruas com o objetivo de conscientizar a comunidade a partir da distribuição de panfletos, que continham os resultados do projeto que retratam a problemática do lixo na cidade de Apodi, assim como medidas simples que podem ser realizadas pela população no dia-a-dia, uma vez que todos são responsáveis pela produção de lixo.

É papel da escola levar à reflexão os problemas da comunidade, orientando seus alunos na busca de soluções para os desafios encontrados e implantar uma educação voltada para o meio ambiente. Desse modo, a escola atingirá um nível de integração e inter-relacionamento indispensáveis à execução de projetos que venham a auxiliar a comunidade na qual ela se insere (GONÇALVES, 1989).

De acordo com o entrevistado, quando indagado sobre como os discentes e comunidade em geral observa os problemas ambientais, os alunos: "sempre são ativos. Gostam de sair do ambiente escolar e a resposta é sempre 
satisfatória". Já quanto à comunidade, "sempre foram receptivos quando abordados por alunos durante os trabalhos". O envolvimento dos alunos em tais atividades, e a aceitação da comunidade durante a realização dos respectivos trabalhos, são aspectos bastante positivos.

Mais que envolver a comunidade intra e extraescolar, os projetos devem criar "canais de comunicação com a população para incrementar a discussão e reflexão sobre o papel dos cidadãos em relação ao ambiente" (VEIGA; AMORIM; BLANCO COSSÍO, 2005, p. 21).

Seniciato e Cavassan (2008) afirmam que as aulas de Ciências desenvolvidas fora do ambiente escolar trazem consigo maior motivação, envolvimento e interesse se comparadas às aulas tradicionais.

Para que ocorra o encaminhamento no sentido de promover o desenvolvimento local sustentável, os diversos sujeitos sociais precisam estar envolvidos em um trabalho consistente de Educação Ambiental (ROCHA, 2005).

Sobre a décima questão, que abordava a obtenção de informações sobre a Educação Ambiental, o docente não foi específico, porém enfatizou que o conteúdo programático do livro didático contempla a contento a abordagem da EA.

\section{Conclusões}

O estudo realizado através dos questionários com os alunos, expõe que uma parte considerável destes ainda não se sentem integrante do meio ambiente. Mas muito já vem sendo realizado, nota-se o discernimento dos alunos quanto às questões ligadas à temática, quando se coloca uma situaçãoproblema, e boa parte opta por decisões sanariam a causa dos problemas.

O período de observação, aliado à análise de questionários permitiu perceber que a interdisciplinaridade vem sendo trabalhada de forma eficiente na referida turma, durante a disciplina de Ciências, conforme orientada pela Lei no. 6.938/81 e PCN's. Onde o docente sempre procura uma maneira de relacionar os conteúdos ministrados com temáticas voltadas ao meio ambiente, assim como associa aos problemas cotidianos dos alunos.

Considera-se de grande importância as atividades extracurriculares que são realizadas com a turma, como os projetos que sensibilizam os discentes e a comunidade, pois eles geram ações individuais capazes de instigar comportamentos ambientalmente corretos.

Porém ainda é necessário que se abra mais espaço para que a temática ambiental seja trabalhada, de modo que se possa obter um melhor aproveitamento. Faz-se necessário também que haja um maior interesse por parte dos demais docentes. Sabendo é imprescindível trabalhar a Educação Ambiental, visto que todos nós somos responsáveis pela saúde do planeta. 


\section{Agradecimentos}

A Fundação de Amparo à Pesquisa e ao Desenvolvimento Científico e Tecnológico do Maranhão - FAPEMA, pelo fomento desta pesquisa. Ao professor alvo desta análise, Makson Rangel, pela solicitude em cooperar com o trabalho e, em especial, aos meus orientadores, Antonia e Osiel, por confiarem e apoiarem este estudo.

\section{Referências}

AMOÊDO, J. B. A Educação Ambiental como processo de conscientização e compromisso social. Revista Metáfora Educacional, n. 9, p. 31-56, dez. 2010.

ANDRADE, F. T. de; MUSSE, N. S. O. Análise da percepção ambiental de alunos do ensino fundamental de uma escola pública de Martins - RN. In: Semana de Estudos, Teorias e Práticas Educativas, 5., 2014. Anais ... S.I: Editora Realize, $2014 . \quad$ Disponível em: <http://www.editorarealize.com.br/revistas/setepe/trabalhos/Modalidade 1datah ora 24092014192435 idinscrito 123 bfc61f66adf70998ed46a00a7c211 212.pdf >. Acesso em: 29 setembro de 2017.

BACCI, D. L. C.; PATACA, E. M. Educação para Água. Revista de Estudos Avançados, v. 22, n. 63, mai./ago. 2008.

BACCI, D. L.C. et al. Educando nas águas do Pijuçara - uma proposta de Educação Ambiental. Revista Cultura e Extensão USP, v. 2, p. 41-53, 2009, São Paulo.

BARIZAN, A.C.C.; DAIBEN, A.M.L.; RUIZ, S. S. As representações sociais de meio ambiente e de Educação Ambiental e as potenciais práticas pedagógicas de alunos do curso de licenciatura em Ciências biológicas da UNESP de Bauru, SP. In: Encontro Pesquisa em Educação Ambiental: Abordagens epistemológicas e metodológicas, 2., p. 1-14, 2003, São Carlos, Anais eletrônicos... São Carlos: UFSCar. Disponível em: $<$ http://www.epea.tmp.br/epea2003 anais/pdfs/plenary/68.pdf>. Acesso em: 06 janeiro de 2018.

BAUMGRATZ, N. D. P. Educação Ambiental além dos muros da escola: uma experiência no Parque Nacional do Itatiaia. 2014. 299f. Dissertação (Mestrado em Ciências da Saúde e do Meio Ambiente) - Centro Universitário de Volta Redonda - UniFOA, Volta Redonda, 2014.

BOFF, L. Ecologia \& capitalismo: simplesmente incompatíveis. Revista Beijaflor, Curitiba, ano 4, p.8-9, out. 2009.

BRASIL. Lei n. 6.938 , de 31 de agosto de 1981. Dispõe sobre a Política Nacional do Meio Ambiente, seus fins e mecanismos de formulação e aplicação, e dá outras providências. Disponível em: http://www.planalto.gov.br/ccivil 03/Leis/L6938.htm. Acesso em: 05 junho de 2016. 
BRASIL. Ministério da Educação e Cultura. Parâmetros Curriculares Nacionais: meio ambiente e saúde. v. 9. Brasília, 1997. 128p.

BRASIL. Ministério da Educação e do Desporto. Secretaria da Educação Fundamental. Parâmetros Curriculares Nacionais. Brasília: MEC/SEF, 1998, p.57.

CANESIN, F. P.; SILVA, O. C. V.; LATINI, R. M. O olhar de um licenciando para o ensino de química e a Educação Ambiental. Revista Eletrônica do Mestrado Profissional em Ensino de Ciências da Saúde e do Ambiente, v.3, n. 2, p.50-60, 2010.

CAVALHEIRO, J. S. Consciência ambiental entre alunos e professores da Escola Estadual Básica Dr. Paulo Devanier Lauda. 2008. 51f. Monografia (Especialização em Educação Ambiental) - Universidade Federal de Santa Maria, Santa Maria, 2008.

CUNHA, T. S.; ZENI, A. L. B. A Representação Social de Meio Ambiente para alunos de Ciências e Biologia: subsídio para atividades em Educação Ambiental. Revista Eletrônica do Mestrado em Educação Ambiental, Rio Grande, v.18, p. 151-162, 2007.

DACACHE, F.M. Uma proposta de Educação Ambiental utilizando o lixo como tema interdisciplinar. 2004. 80f. Dissertação (Mestrado em Ciência Ambiental) - Universidade Federal Fluminense, Niterói, 2004.

DIAS, G. F. Educação Ambiental: princípios e práticas. 9.ed. São Paulo: Gaia, 2004.

FERREIRA, E. Educação Ambiental e desenvolvimento de práticas pedagógicas sob um novo olhar da ciência química / Edicarlo Ferreira. Dissertação (Mestrado em Educação) - Americana: Centro Universitário Salesiano de São Paulo, 2010. 115f. Disponível em: https://unisal.br/wpcontent/uploads/2013/04/Disserta\%C3\%A7\%C3\%A30 Edicarlo-Ferreira.pdf.

Acesso em: 01 de outubro de 2017.

FREIRE, P. Pedagogia da autonomia: saberes necessários à prática educativa. São Paulo: Paz e Terra, 2002.

GONÇALVES, D. Educação Ambiental: garantia de vida. Rio de Janeiro: UFF, 1989.

GUIMARÃES, Z. F. S. et al. Projetos de Educação Ambiental em escolas: a necessidade da sistematização para superar a informalidade e o improviso. Pesquisa em Educação Ambiental, vol. 7, n. 1, p. 67-84, 2012.

LAYRARGUES, P.P. O Cinismo da Reciclagem: o significado ideológico da reciclagem da lata de alumínio e suas implicações para a Educação Ambiental. In. LOUREIRO, C.F.B. (org.) LAYRARGUES, P.P.; CASTRO, R.S.(orgs.). Educação Ambiental: repensando o espaço da cidadania. $5^{\underline{a}}$ ed. São Paulo: Cortez, 2011. p.185-225. 
LEITE, R.F.; RODRIGUES, M.A. Educação Ambiental e Ensino de Química: o que dizem os professores. Encontro Nacional de Pesquisa em Educação em Ciências. 9., 2013, Águas de Lindóia. Anais... Águas de Lindóia: [s.n], 2013. Disponível em: <http://www.nutes.ufrj.br/abrapec/ixenpec/atas/resumos/R05741.pdf>. Acesso em: 30 setembro de 2017.

LIMA, P. G. Formação de professores: por uma ressignificação do trabalho pedagógico na escola. Dourados: Ed. UFGD, 2010.

MARCZWSKI, M. Avaliação da percepção ambiental em uma população de estudantes do Ensino Fundamental de uma escola municipal rural: estudo de caso. 2006. 187f. Dissertação (Mestrado em Ecologia) - Universidade Federal do Rio Grande do Sul, Porto Alegre, 2006.

MEDEIROS, E.A. de.; AMORIM, G.C.C. Análise textual discursiva: dispositivo analítico de dados qualitativos para a pesquisa em educação. Laplage em Revista, Sorocaba, vol.3, n.3, set.-dez. 2017, p.247-260.

MÓNICO, L; ALFERES, V; PARREIRA, P; CASTRO, P. A. A Observação Participante enquanto metodologia de investigação qualitativa. In: Atas Investigação Qualitativa em Ciências Sociais. v. 3, 2017. Disponível em: $<$ https://proceedings.ciaiq.org/index.php/ciaiq2017/article/view/1447/1404>. Acesso em: 6 de janeiro de 2018.

MORAIS, A. E. R. de; BARBOSA, P. T.; ALVES, L. A. Avaliação dos impactos socioambientais urbanos: o descarte incorreto dos resíduos e atividade de conscientização ambiental na cidade de Apodi - RN. Revista Eletrônica em Gestão, Educação e Tecnologia Ambiental, Santa Maria, v. 20, n. 1, p. 295305, jan./abr. 2016.

MORAN, J. M. O vídeo na sala de aula. Comunicação e Educação. São Paulo, v.2, p.27-35, 1995

OLIVEIRA, A.L.; OBARA, A.T.; RODRIGUES, M.A. Educação Ambiental: comcepções e práticas de professores de ciências do ensino fundamental. Revista Electrónica de Enseñanza de las Ciencias, vol. 6, n.3, p.471 - 495, 2007.

PORTILHO, M. F. Profissionais do lixo: um estudo sobre engenheiros, garis e catadores. 1997. Dissertação (Mestrado em Psicologia de Comunidades) Universidade Federal do Rio de Janeiro, Rio de Janeiro, 1997.

RAMOS, E.S. et al. Análise da Prática em Educação Ambiental de Professores de Química. In: 1 CONGRESSO PARANAENSE DE EDUCAÇÃO EM QUÍMICA. 2009. Londrina. Anais... UEL: Londrina, 2009. Disponível em: http://www.uel.br/eventos/cpequi/Completospagina/18274052720090622.pdf.

Acesso em: 03 outubro de 2017.

REIS, H. B. C. dos. Os impactos da globalização sobre o meio ambiente: uma introdução à análise da Comunicação Social. Contemporânea, n. 4, p. 169180, 2005. 
ROCHA, M. M. de F. Turismo, Desenvolvimento Local e Sustentabilidade: Um Estudo de Caso no Município de Itatiaia - RJ. 2005. 173 f. Dissertação (Mestrado em Ciência Ambiental) - Universidade Federal Fluminense, Niterói, 2005.

ROCHA, N. D.; ROCHA, J. M. da; HAMMES, L. J. Educação Ambiental transformadora: epistemologia e prática educativa. Revista Eletrônica do Mestrado em Educação Ambiental, v. 33, n.2, p. 268-285, mai./ago. 2016.

SANTOS, A. Complexidade e transdisciplinaridade em educação: cinco princípios para resgatar o elo perdido. Revista Brasileira de Educação. v. 13. n. 37, jan./abr., 2008.

SANTOS, M. A. P. dos; CRUZ COPETTI, A. C. C. Análise e sensibilização dos alunos de uma escola pública nas ações sobre Educação Ambiental. Revista Monografias Ambientais/UFSM, v. 14, p.18-24, 2015.

SENICIATO, T.; CAVASSAN, O. Afetividade, motivação e construção de conhecimento científico nas aulas desenvolvidas em ambientes naturais. Ciências e Cognição. v. 13, n.3, p. 120-136, 2008.

SILVA, A. da; HAETINGER, C. Educação Ambiental no Ensino Superior - O Conhecimento a favor da qualidade de vida e da conscientização socioambiental. Revista Contexto \& Saúde, v. 12, n. 23, p. 34-40, jul./dez., 2012.

SILVA, D. de S. Análise epistemológica sobre a questão ambiental na formação docente: com um olhar exploratório no curso de Licenciatura em Química do Instituto Federal do Maranhão - Campus Zé Doca. 2017. 98f. Monografia (Licenciatura em Química). Instituto Federal de Educação, Ciência e Tecnologia do Maranhão - Campus Zé Doca, Zé Doca, 2017.

SONDA, A. K. A Importância da Educação Ambiental no Ensino de Ciências. 2011. 34 f. Monografia (Especialização em Ensino de Ciências) - Universidade Tecnológica Federal do Paraná, Medianeira, 2011.

TEIXEIRA, R. da S.; SOUZA, R. O. L de. Análise de materiais educativos utilizados como ferramenta para a Educação Ambiental de estudantes de escolas públicas do Rio de Janeiro. Revista Eletrônica em Gestão, Educação e Tecnologia Ambiental. Santa Maria, v. 19, n. 2, p. 1032-1037, maio/ago. 2015.

VEIGA, A.; AMORIM, É. P.; BLANCO COSsíO, M. Um Retrato da Presença da Educação Ambiental no Ensino Fundamental Brasileiro: o percurso de um processo acelerado de expansão. Brasília: INEP, 2005.

WHITEHEAD, A. N. O conceito de Natureza. Tradução de Júlio B. Fischer. São Paulo: Martins Fontes, 1994, p. 9. 